I N S T I T U T O

DE

M E D I C I N A

T R O P I C A L

DE

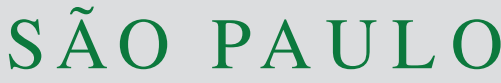

JOURNAL OF THE SÃO PAULO INSTITUTE OF TROPICAL MEDICINE

'Universidade de Pernambuco, Recife, Pernambuco, Brazil

²Secretaria de Saúde, I Região de Saúde, Departamento da Vigilância em Saúde, Recife, Pernambuco, Brazil

${ }^{3}$ Fundação Oswaldo Cruz, Instituto Aggeu Magalhães, Recife, Pernambuco, Brazil

${ }^{4}$ Universidade Federal de Pernambuco, Recife, Pernambuco, Brazil

${ }^{5}$ Ministério da Saúde, Brasília, DF, Brazil

Correspondence to: Cintia Michele Gondim de Brito

Universidade de Pernambuco,

Rua Arnóbio Marques, 310, Santo Amaro, CEP 50100-130, Recife, PE, Brazil

E-mail: cintiabrito.lima@gmail.com

Received: 5 November 2020

Accepted: 12 March 2021

\section{Prevalence of trachoma in Pernambuco State, Brazil (2014-2015)}

\author{
Cintia Michele Gondim de Brito ${ }^{1,2}$, Zulma Maria de Medeiros ${ }^{1,3}$, Celivane \\ Cavalcanti Barbosa ${ }^{(2,3}$, Ulisses Ramos Montarroyos ${ }^{(1)} 1$, Cristiano Ferraz ${ }^{(1)}$, \\ Marcel de Toledo Vieira ${ }^{(4}$, Maria de Fátima Costa Lopes ${ }^{5}$, Giselle \\ Campozana Gouveia ${ }^{3}$
}

\section{ABSTRACT}

To estimate the prevalence of cases of trachoma in the population at social risk aged 1-9 years in Pernambuco State and its mesoregions. This was a cross-sectional study in which secondary data from the National Household Survey on Trachoma (2014-2015) were analyzed. The study covered 96 census tracts distributed across the mesoregions of Pernambuco State (Metropolitan Region of Recife, Zona da Mata, Agreste, Sertao do Sao Francisco and Sertao Pernambucano). The study included all homes with children aged 1-9 years, and all of them were examined for trachoma, using the WHO criteria. Among the total of 7,423 children aged 1-9 years who participated in this survey, 446 presented with active trachoma. Thus, the prevalence of trachoma in Pernambuco State, in children between 1-9 years old was $6.65 \%$, and it was higher among children aged 5-9 years (7.12\%) and among girls (7.23\%). This result was seen in the majority of the mesoregions studied, except in the Zona da Mata and Sertao do Sao Francisco, where there were higher prevalences in the age group of 1-4 years (5.55\%) and among boys $(5.90 \%)$. A tendency towards a higher prevalence between 1 and 6 years of age was observed. The follicular trachoma continues to be an important public health problem in Pernambuco State. It particularly affects poor people, including those living in urban areas of the State.

KEYWORDS: Follicular trachoma. Chlamydia trachomatis. Prevalence. Prevention and control. Epidemiological surveillance.

\section{INTRODUCTION}

Trachoma is a neglected disease caused by Chlamydia trachomatis ${ }^{1}$. It is directly transmitted, particularly in domestic environments ${ }^{2}$. Children with active infection, aged up to 10 years old are the main reservoir for this endemic disease ${ }^{3,4}$. There are five clinical forms of this disease and their diagnosis is essentially based on clinical and epidemiological data: trachomatous follicular inflammation (TF); trachomatous intense inflammation (TI); trachomatous scarring (TS); trachomatous trichiasis (TT) and corneal opacification (CO). Transmission occurs between individuals with active infection who present the TF and TI forms, but sequelae occur in TS, TT and CO forms ${ }^{5}$.

This disease continues to be an important public health problem that causes visual deficiencies. The World Health Organization (WHO) has estimated that there are 41 million people with active trachomatous infection worldwide and 7.6 million people with TT, while 1.3 million present with serious visual impairment and blindness caused by trachoma ${ }^{6,7}$. 
The highest prevalences of trachoma in the world are in African countries, in the Western Pacific region and in Southeast Asia ${ }^{8}$. It is mainly transmitted in populations living in poor rural areas in underdeveloped countries ${ }^{9}$, i.e. among people living under poor sanitation conditions and water supply ${ }^{10-12}$. Nonetheless, trachoma continues to be endemic in more than 50 countries, including Brazil ${ }^{13}$.

In Brazil, detection of trachoma is a task under the responsibility of States, the federal district and municipalities, with support from the Ministry of Health. These entities are tasked with organizing surveys to detect and treat cases aiming to reduce the prevalence of the disease and control it, and to notify these activities through the official information system ${ }^{5,14}$. Between 2002 and 2008, a survey conducted in Brazilian schools found that the prevalence of "active infection" was 5\%. However, some areas were found to have rates higher than $5 \%$, which was indicative of an endemic disease that was not under control ${ }^{5}$.

Trachoma is among the preventable causes of blindness. The WHO Global Elimination of Trachoma program (GET 2020) has the aim of eradicating trachoma as a cause of blindness around the world by the year $2020^{15}$. Brazil is a program signer but has not yet reached the target of eliminating trachoma, despite making a commitment to do so by the year $2015^{13}$.
Over the last few years, studies on trachoma have been conducted in different regions and States of Brazil, revealing a high diversity among the populations studied and large variations in estimates of the prevalence of trachoma, with different degrees of severity,5,11,14.

Several authors have pointed out the need for new studies in Brazil, with the aim of identifying the prevalence of trachoma ${ }^{1,5,11,14}$. However, this need would be for householdbased surveys, given that those conducted previously were school-based ${ }^{11,14}$. Therefore, the present study aimed at estimating the household-based prevalence of cases of trachoma among the population aged 1-9 years, living in areas at social risk in Pernambuco State.

\section{MATERIALS AND METHODS}

The study design was defined as cross-sectional, given the need to ascertain the prevalence of trachoma in the population aged 1-9 years that was at social risk. The study area comprised the five mesoregions of Pernambuco State, in Northeastern Brazil: Metropolitan Region of Recife, Zona da Mata, Agreste, Sertao do Sao Francisco and Sertao Pernambucano (Figure 1). The estimated children between 1-9 years old in 2014 was 9,252,442 inhabitants $(4,446635 \text { boys and } 4,805,807 \text { girls })^{16}$.

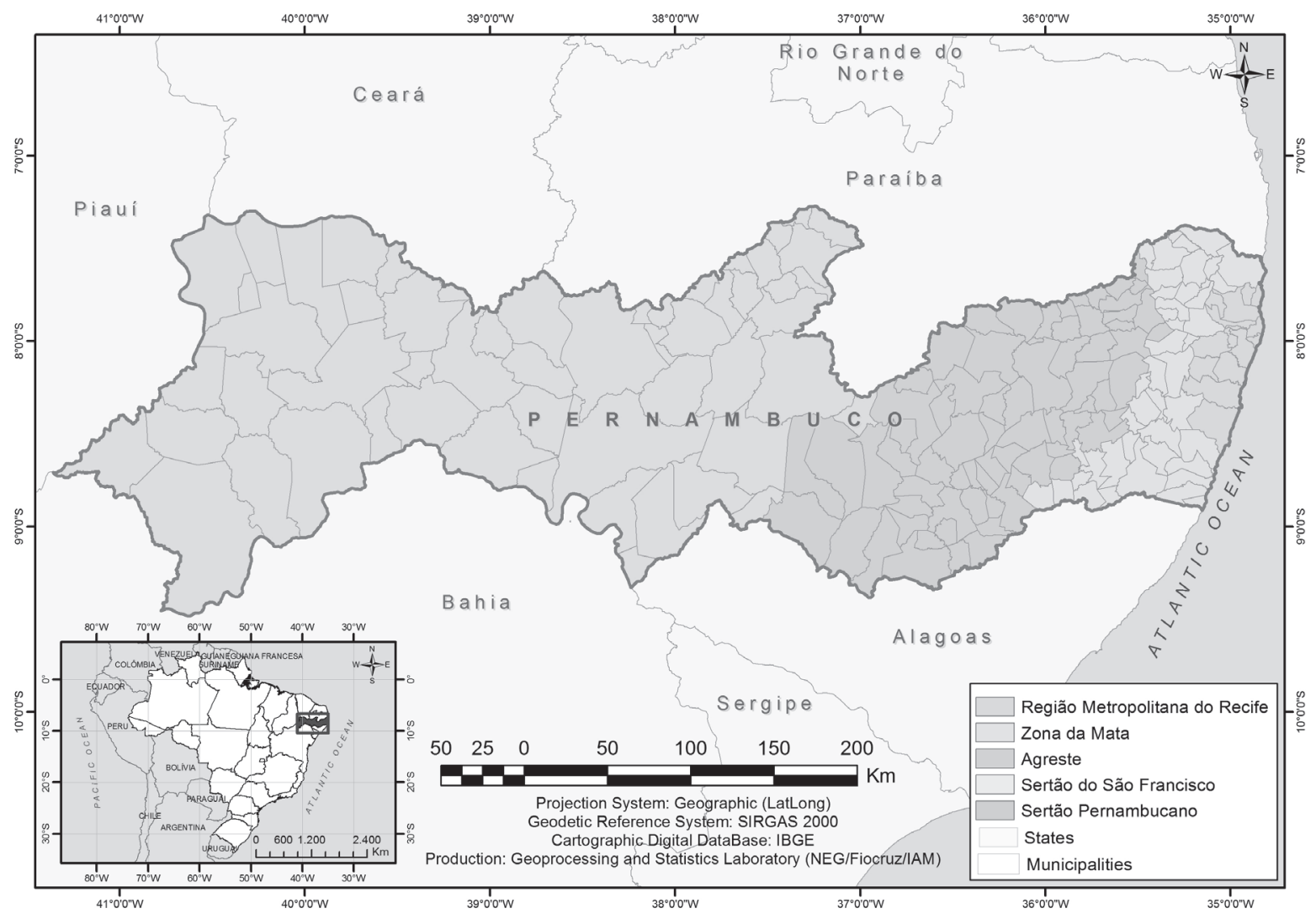

Figure 1 - Geographic location of Pernambuco State and its division by mesoregions. 
This study consisted of an analysis of secondary data from the National Household Survey on Trachoma that was conducted between 2014 and $2015^{17}$. The following parameters were used to select the sample: prevalence of active trachoma of 5\%, confidence interval of $95 \%$, maximum margin of error of 0.02 and correction factor for finite populations with an effect of $4^{4}$. Active trachoma was considered to be the clinical inflammatory forms of the disease (TF and / or TI) and they are called active trachoma because they are transmissible and must be treated ${ }^{18}$.

The prevalence and the number of cases of trachoma were defined in accordance with the WHO criteria, in which it is considered that trachoma has been eliminated as a cause of blindness in a given area when the prevalence of TF among children aged 1-9 years in that area is less than $5 \%$.

Census tracts with the following characteristics were eligible for the criterium of low socioeconomic status: at least $50 \%$ of the households with a per capita household income of not more than $1 / 4$ of a monthly minimum wage; and less than $95 \%$ of the households with connection to the general water supply network.

In this manner, 1,778 census tracts were found to be eligible. Out of these, a sample of 96 census tracts was drawn for screening. The criteria for excluding households in these census tracts were the following: no children in the age group of interest; legal guardians of these children were not present; home found to be unoccupied at the time of three visits by the team; and refusal of the householders to participate.

All children aged between 1 and 9 years in the households were included and examined, provided that their legal guardians agreed to this, through signing a free and informed consent statement.

Case confirmation was essentially achieved through a clinical diagnosis, by means of an external ocular examination using a magnifying glass $(2.5 \mathrm{X})$, under either natural or artificial illumination, performed by trained and standardized examiners ${ }^{18}$. All the clinical forms of trachoma were investigated, and individuals presenting with trachoma were notified and referred for treatment.

The prevalence of trachoma was calculated considering the $95 \%$ confidence interval (CI) for each study location (Pernambuco and its mesoregions), according to gender and age. The database provided by the survey was adjusted by applying a correction factor ${ }^{17}$. The data were adjusted by applying a correction factor to account for random effects and cluster sample sizes ${ }^{19,20}$. Weights and clusters were adjusted through the Generalized Linear and Latent Mixed Model (GLLAM) method ${ }^{20}$.

The software used in this study comprised: Microsoft Excel (version XP 2010, Microsoft, Redmond, WA, EUA) and, for data analysis, the STATA Software (version 12.0, StataCorp, Chicago, IL, EUA). The project was approved by the research ethics committee of the Oswaldo Cruz Foundation, in Pernambuco (CAEE 21192013.0.0000.5190).

\section{RESULTS}

A total of 4,238 households were evaluated, examinations were performed on 7,423 children aged 1-9 years, and 446 cases of active trachoma were found, which were all in the follicular inflammatory form. The prevalence of trachoma for the entire Pernambuco State was $6.65 \%$ (CI 5.39-8.17), with prevalences $>5 \%$, except in the mesoregion of the Sertao Pernambucano. The Metropolitan Region of Recife had a prevalence rate of $6.41 \%$ (CI 5.02-8.15), and most of the trachoma cases in this region were living in urban areas of the municipalities (Table 1).

Table 2 presents the prevalence of trachoma according to age group andgender . In terms of age groups, 2,922 children aged 1-4 years were examined, among whom 155 cases were diagnosed; and 4,501 children aged 5-9 years were examined, among whom 291 cases were detected. The

Table 1 - Prevalence of trachoma in Pernambuco State and its mesoregions, years 2014 and 2015.

\begin{tabular}{lcccc}
\hline Locality & Number of examined & Number of cases & Prevalence (\%) & $\mathrm{Cl}^{\mathrm{c}}(95 \%)$ \\
\hline $\begin{array}{l}\text { Pernambuco State } \\
\text { Mesoregions }^{\mathrm{b}}\end{array}$ & 7,423 & 446 & 6.65 & $5.39-8.17$ \\
$\quad$ & & & & \\
RMR & 1,535 & 101 & 6.41 & $5.02-8.15$ \\
Zona da Mata & 1,322 & 63 & 4.88 & $3.45-6.86$ \\
$\quad$ Agreste & 1,655 & 148 & 8.87 & $6.70-11.65$ \\
$\quad$ Sertao do Sao Francisco & 1,361 & 77 & 5.28 & $2.71-10.04$ \\
$\quad$ Sertao Pernambucano & 1,550 & 57 & 3.83 & $2.73-5.36$ \\
\hline
\end{tabular}

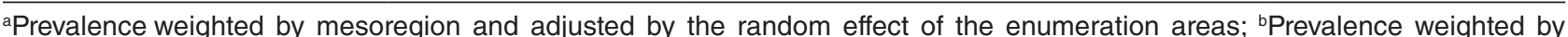
municipality of the mesoregion and adjusted by the random effect of the census sector; ${ }^{\circ}$ Confidence Interval 
respective prevalences were $5.87 \%$ (CI 4.77-7.23) and $7.12 \%$ (CI 5.57-9.07). There was a higher prevalence of trachoma among children aged 5-9 years, throughout Pernambuco except in the Zona da Mata (Table 2). The Sertao Pernambucano had prevalence rates of less than 5\% for both investigated age groups.

In relation to gender, there were more cases among girls, comprising 238 cases and prevalence of $7.23 \%$ (CI 5.74-9.04). However, in the mesoregion of the Sertao do Sao Francisco, boys were more often infected than were girls (Table 2).

Figure 2 shows that the number of cases increased in older ages, up to six years. The number of cases among girls corresponded to an important proportion of this increment,

Table 2 - Prevalence of trachoma in Pernambuco State and its mesoregions according to age and gender, years 2014 and 2015.

\begin{tabular}{|c|c|c|c|c|}
\hline Locality & Number of examined & Number of cases & Prevalence (\%) & $\mathrm{Cl}^{\mathrm{c}}(95 \%)$ \\
\hline \multicolumn{5}{|l|}{ Pernambuco State ${ }^{a}$} \\
\hline \multicolumn{5}{|l|}{ Age Group } \\
\hline From 1 to 4 years & 2,922 & 155 & 5.87 & $4.77-7.23$ \\
\hline From 5 to 9 years & 4,501 & 291 & 7.12 & $5.57-9.07$ \\
\hline \multicolumn{5}{|l|}{ Gender } \\
\hline Male & 3,849 & 208 & 6.12 & $4.69-7.96$ \\
\hline Female & 3,574 & 238 & 7.23 & $5.74-9.04$ \\
\hline \multicolumn{5}{|l|}{ Mesoregions $^{\mathrm{b}}$} \\
\hline \multicolumn{5}{|l|}{ RMR } \\
\hline \multicolumn{5}{|l|}{ Age Group } \\
\hline From 1 to 4 years & 633 & 37 & 5.38 & $3.57-8.02$ \\
\hline From 5 to 9 years & 902 & 64 & 7.11 & $5.45-9.22$ \\
\hline \multicolumn{5}{|l|}{ Gender } \\
\hline Male & 793 & 45 & 5.96 & $4.20-8.41$ \\
\hline Female & 742 & 56 & 6.91 & $4.63-10.2$ \\
\hline \multicolumn{5}{|l|}{ Zona da Mata } \\
\hline \multicolumn{5}{|l|}{ Age Group } \\
\hline From 1 to 4 years & 523 & 28 & 5.55 & $3.86-7.91$ \\
\hline From 5 to 9 years & 799 & 35 & 4.44 & $2.88-6.77$ \\
\hline \multicolumn{5}{|l|}{ Gender } \\
\hline Male & 690 & 26 & 3.89 & $2.72-5.53$ \\
\hline Female & 632 & 37 & 5.96 & $3.80-9.22$ \\
\hline \multicolumn{5}{|l|}{ Agreste } \\
\hline \multicolumn{5}{|l|}{ Age Group } \\
\hline From 1 to 4 years & 601 & 47 & 8.11 & $6.31-10.4$ \\
\hline From 5 to 9 years & 1,054 & 101 & 9.31 & $6.50-13.2$ \\
\hline \multicolumn{5}{|l|}{ Gender } \\
\hline Male & 834 & 68 & 8.46 & $5.95-11.9$ \\
\hline Female & 821 & 80 & 9.30 & $6.59-13.0$ \\
\hline \multicolumn{5}{|c|}{ Sertao do Sao Francisco } \\
\hline \multicolumn{5}{|l|}{ Age Group } \\
\hline From 1 to 4 years & 570 & 25 & 3.72 & $1.70-7.91$ \\
\hline From 5 to 9 years & 791 & 52 & 6.45 & $3.29-12.2$ \\
\hline \multicolumn{5}{|l|}{ Gender } \\
\hline Male & 691 & 43 & 5.90 & $2.61-12.8$ \\
\hline Female & 670 & 34 & 4.65 & $2.60-8.19$ \\
\hline \multicolumn{5}{|l|}{ Sertao Pernambucano } \\
\hline \multicolumn{5}{|l|}{ Age Group } \\
\hline From 1 to 4 years & 595 & 18 & 2.69 & $1.63-4.38$ \\
\hline From 5 to 9 years & 955 & 39 & 4.54 & $3.17-6.47$ \\
\hline \multicolumn{5}{|l|}{ Gender } \\
\hline Male & 841 & 26 & 3.24 & $1.96-5.31$ \\
\hline Female & 709 & 31 & 4.57 & $3.12-6.63$ \\
\hline
\end{tabular}

aWeighted by mesoregion and adjusted by the random effect of the census tract enumeration areas; ${ }^{\text {bWeighted by municipality of }}$ the mesoregion and adjusted by the random effect of the census sector; 'Confidence Interval 
given that this number was greater at most investigated ages (Figure 3).

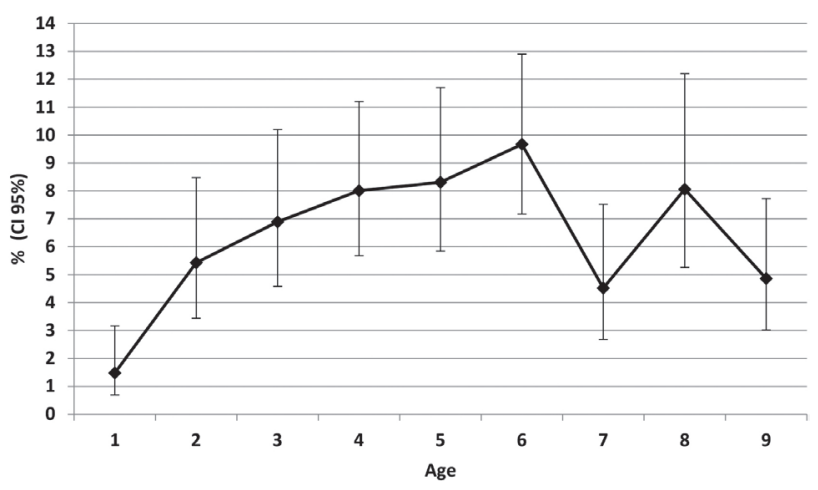

Figure 2 - Distribution of positive cases of trachoma in Pernambuco State according to age and confidence intervals, years 2014 and 2015.

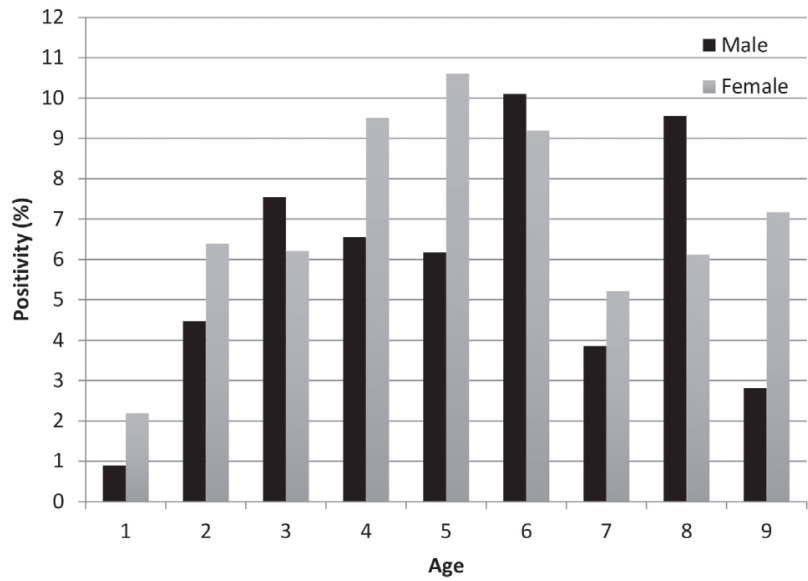

Figure 3 - Distribution of positive cases of trachoma in Pernambuco State according to age and gender, years 2014 and 2015.

\section{DISCUSSION}

This household survey showed a high prevalence of follicular trachoma among children aged 1-9 years living in Pernambuco State. Through stratification of the State, it was observed that in $80 \%$ of the area, more than $5 \%$ of the sample presented with active trachoma. This was especially true in the Metropolitan Region of Recife, where TF was identified in urban areas. The sample of the present study was larger than those of all the school-based surveys conducted in Brazil $^{2,5,10,11,14}$.Moreover, this was the first survey on trachoma in Brazil to use households as the sampling unit.

Thus, it is plausible to accept that the prevalence of trachoma was underestimated in the earlier school-based surveys. In those surveys, the age group from 1 to 4 years was not fully investigated. Schools are often targeted for evaluations and interventions regarding diseases because of the easier access to and the availability of the children.
However, a household-based investigation conducted in four African countries (Nigeria, Ethiopia, Mali and Niger) found that trachoma was more common among children of preschool age than among children of school age ${ }^{21}$.

In Brazil, only a minority of children aged 0-4 years are enrolled in daycare centers. For most children in this age group, their homes and immediate surroundings are the only places where they have social contact. Corroborating the findings of the study conducted in Africa ${ }^{21}$, only a single mesoregion of Pernambuco presented more cases among children of preschool age, compared with those of school age. However, the prevalence found in the age group from 1 to 4 years was higher than 5\%, except in two areas of the Sertao mesoregion. Bero et al. ${ }^{15}$ stated that these age groups were the main reservoir of the etiological agent in populations in which trachoma is endemic, and that with increasing of age, the prevalence reduces because of better hygiene practices or a buildup of partial immunity, leading to to a diminished risk of the infection or duration of infection among children ${ }^{22-26}$.

WHO considers that trachoma is under control when its prevalence in the active form is less than 5\% among children aged 1-9 years ${ }^{5,14}$, The present study shows that measures for the monitoring and surveillance of trachoma need to be implemented, in conjunction with intersectoral health promotion actions, improvements to socioeconomic conditions and education for the population ${ }^{9}$, especially with attention to TF among children.

In the present study, 446 cases of active trachoma were diagnosed, with growth of the sample as age increased, up to the age of six years. According to Ferede et $_{\text {al }}{ }^{22}$, the age at the onset of infection influences the evolution of the disease, such that the earlier the disease starts, the greater the severity ${ }^{22}$. Healthcare services should therefore be prepared to attend to sequelae such as TS, TT and CO among adults and elderly people. Regarding the differences in the prevalence of trachoma among the five mesoregions studied, three of them presented with prevalences higher than the one recommended by the WHO criteria ${ }^{5,14}$. This indicates the importance of integrating proactive surveillance actions. One proposal for this surveillance that would be feasible in Brazil would consist of a healthcare model in which family health teams would care for children of preschool ages and school health teams would care for children of school age.

According to Alves et al. ${ }^{11}$, many municipalities in Pernambuco State have never received any interventions from the healthcare sector regarding active searching for cases of trachoma, associated with treatment, not even among school children. Surveys on trachoma in these municipalities might reveal a transmission chain for trachoma within Pernambuco State ${ }^{11}$. This possibility, 
together with the difficulty in gaining access to children who are not regularly enrolled in schools, favors the maintenance of the disease in communities that are in greatest need to assistance due to social restrictions both in rural areas and in urban areas, as seen in the Metropolitan Region of Recife.

Girls presented TF more frequently than did boys, both at preschool and at school ages. Corroborating the results of our study, King et al. ${ }^{21}$ showed that girls were more often infected and that younger girls were at greater risk of contracting follicular trachoma ${ }^{21}$. Although the analysis of results according to the gender did not show any significant difference, there were more cases of the disease among girls, just like in studies conducted in other countries around the world ${ }^{7,27,28}$, and studies conducted in Brazil among schoolage population $5^{5,14}$. It is possible that the higher frequency of trachoma among girls may be due to the more affective behavior of girls, along with a genetically-determined increased susceptibility towards immuno-inflammatory reactions of greater intensity to infection by Chlamydia trachomatis $^{29}$.

The results found here corroborated those from surveys in schools conducted by Ferraz et al. ${ }^{30}$ Meneghim et al. ${ }^{13}$ and Alves et al. ${ }^{11}$. Those studies showed that trachoma was present in several Brazilian States and that, despite a marked decline in the incidence of this disease over recent decades, it persists. It particularly affects poor people in all regions of Brazil, including urban areas of large cities.

Our study confirms that in endemic areas for trachoma, healthcare services need to be prepared to make this diagnosis in pediatric clinics, especially among children up to the age of nine years. Furthermore, once the cases have been identified, there is a need to implement a surveillance in the homes and in the immediate surroundings, actively searching for cases in children up to the age of six years, and in the school environment, searching for cases in older children, given that identification of cases solely through surveys is a more expensive epidemiological tool than the implementation of measures within the routine healthcare.

\section{ACKNOWLEDGMENTS}

To Fiocruz, the Department of Epidemiological Surveillance of the Ministry of Health (SVS/MS), the State Secretariat of Health of Pernambuco, the managers and advisors of the Sanar Program of Pernambuco, to all technicians and the population that participated in the National Household Survey Trachoma, 2014 and 2015.

\section{FUNDING}

This study was financed in part by the Coordenacao de Aperfeicoamento de Pessoal de Nivel Superior - Brasil (CAPES) - Finance Code 001 and by the National Health Fund, through the agreement TC 210/2011 between FIOCRUZ and the Department of Epidemiological Surveillance of the Ministry of Health (SVS/MS).

\section{CONFLICT OF INTERESTS}

The authors declare that there are no conflicts of interest in conducting this study. The authors alone were responsible for the content and writing of this article.

\section{ETHICAL APPROVAL}

The project was approved by the research ethics committee of the Oswaldo Cruz Foundation, in Pernambuco (CAEE 21192013.0.0000.5190).

\section{REFERENCES}

1. Silva MB, Andrade MS, Oliveira YV, Marques MG, Pinho CM, Lopes KA. Trachoma as cause of blindness: literature review. Int Arch Med. 2017;10:1-9.

2. Mabey DC, Solomon AW, Foster A. Trachoma. Lancet. 2003;362:223-9.

3. Lucena AR, Cruz AA, Akaishi P. Epidemiologia do tracoma em povoado da chapada do Araripe - CE. Arq Bras Oftalmol. 2010;73:271-5.

4. Last AR, Burr SE, Weiss HA, Harding-Esch EM, Cassama E, Nabicassa M, et al. Risk factors for active trachoma and ocular Chlamydia trachomatis infection in treatment-naïve trachomahyperendemic communities of the Bijagós Archipelago, Guinea-Bissau. PLoS Neg1 Trop Dis. 2014;8:e2900.

5. Lopes MF, Luna EJ, Medina NH, Cardoso MR, Freitas HS, Koizumi IK, et al. Prevalence oftrachoma in Brazilian schoolchildren. Rev Saude Publica. 2013;47:451-9.

6. World Health Organization. Trachoma: key facts. [cited 2021 Mar 12]. Available from: https://www.who.int/news-room/ fact-sheets/detail/trachoma

7. Mpyet C, Muhammad N, Adamu MD, Muazu H, Umar MM, Goyol M, et al. Prevalence of trachoma in Kano State, Nigeria: results of 44 local government area-level surveys. Ophthalmic Epidemiol. 2017;24:195-203.

8. Ferede AT, Dadi AF, Tariku A, Adane AA. Prevalence and determinants of active trachoma among preschool-aged children in Dembia District, Northwest Ethiopia. Infect Dis Poverty. 2017;6:128.

9. Mpyet C, Muhammad N, Adamu MD, Muazu H, Umar MM, Goyol M, et al. Prevalence of trachoma in Katsina State, Nigeria: results of 34 district-level surveys. Ophthalmic Epidemiol. 2016;23 Suppl 1:55-62. 
10. Tadesse B, Worku A, Kumie A, Yimer SA. Effect of water, sanitation and hygiene interventions on active trachoma in North and South Wollo zones of Amhara Region, Ethiopia: a quasi-experimental study. PLoS Negl Trop Dis. 2017;11:e0006080.

11. Alves FA, Souza WV, Luna CF, Gouveia GC. Análise das intervenções e dos fatores socioambientais associados à ocorrência de tracoma em Pernambuco a partir de dois inquéritos em escolares realizados em 2006 e 2012. Cad Saude Colet. 2016;24:435-42.

12. Taylor HR, Burton MJ, Haddad D, West S, Wright H. Trachoma. Lancet. 2014;384:2142-52.

13. Meneghim RL, Padovani CR, Schellini SA. O tracoma em escolares do município de Botucatu, São Paulo, Brasil detecção e promoção de saúde em uma doença negligenciada. Rev Bras Oftalmol. 2016;75:360-4.

14. Luna EJ, Lopes MF, Medina NH, Favacho J, Cardoso MR. Prevalence of trachoma in schoolchildren in Brazil. Ophthalmic Epidemiol. 2016;23:360-5.

15. Bailey R, Lietman T. The SAFE strategy for the elimination of trachoma by 2020: will it work? Bull World Health Organ. 2001;79:233-6.

16. Instituto Brasileiro de Geografia e Estatística. Censo demográfico: downloads. [cited 2021 Mar 12]. Available from: https:// www.ibge.gov.br/estatisticas/sociais/populacao/9662-censodemografico-2010.html?=\&t=downloads

17. Brito CM, Barbosa CC, Andrade SM, Oliveira AL, Montarroyos UR, Ferraz C, et al. Household survey of trachoma among children living in Pernambuco, Brazil. Pathogens. 2019;8:263.

18. Brasil. Ministério da Saúde. Secretaria de Vigilância em Saúde. Departamento de Vigilância das Doenças Transmissíveis. Manual de vigilância do tracoma e sua eliminação como causa de cegueira. $2^{\text {a }}$ ed. rev. Brasília: Ministério da Saúde; 2014

19. Anderson RM, May RM. Age-related changes in the rate of disease transmission: implications for the design of vaccination programmes. J Hyg (Lond). 1985;94:365-436.

20. Ximenes RA, Martelli CM, Merchán-Hamann E, Montarroyos UR, Braga MC, Lima ML et al. Multilevel analysis of hepatitis A infection in children and adolescents: a household survey in the Northeast and Central-west regions of Brazil. Int J Epidemiol. 2008;37:852-61.

21. King JD, Odermatt P, Utzinger J, Ngondi J, Bamani S, Kamissoko $\mathrm{Y}$, et al. Trachoma among children in community surveys from four African countries and implications of using school surveys for evaluating prevalence. Int Health. 2013;5:280-7.

22. Ferede AT, Dadi AF, Tariku A, Adane AA. Prevalence and determinants of active trachoma among preschool-aged children in Dembia District, Northwest Ethiopia. Infect Dis Poverty. 2017;6:128.

23. Bero B, Macleod C, Alemayehu W, Gadisa S, Abajobir A, Adamu $\mathrm{Y}$, et al. Prevalence of and risk factors for trachoma in Oromia Regional State of Ethiopia: results of 79 population-based prevalence surveys conducted with the Global Trachoma Mapping Project. Ophthalmic Epidemiol. 2016;23:392-405.

24. Bio AA, Boko PM, Dossou YA, Tougoue JJ, Kabore A, Sounouvou I, et al. Prevalence of trachoma in Northern Benin: results from 11 population-based prevalence surveys covering 26 districts. Ophthalmic Epidemiol. 2017;24:265-73.

25. Ketema K, Tiruneh M, Woldeyohannes D, Muluye D. Active trachoma and associated risk factors among children in Baso Liben District of East Gojjam, Ethiopia. BMC Public Health. 2012;12:1105.

26. Abashawl A, Macleod C, Riang J, Mossisa F, Dejene M, Willis R, et al. Prevalence of trachoma in Gambella Region, Ethiopia: results of three population-based prevalence surveys conducted with the Global Trachoma Mapping Project. Ophthalmic Epidemiol. 2016;23 Supp1:77-83.

27. Adera TH, Macleod C, Endriyas M, Dejene M, Willis R, Chu BK, et al. Prevalence of and risk factors for trachoma in Southern Nations, Nationalities, and Peoples' Region, Ethiopia: results of 40 population-based prevalence surveys carried out with the Global Trachoma Mapping Project. Ophthalmic Epidemiol. 2016;23 Suppl 1:84-93

28. Adamu MD, Mpyet C, Muhammad N, Umar MM, Muazu H, Olamiju F, et al. Prevalence of trachoma in Niger State, North Central Nigeria: results of 25 population-based prevalence surveys carried out with the Global Trachoma Mapping Project. Ophthalmic Epidemiol. 2016;23 Suppl 1:63-9.

29. Courtright P, West SK. Contribution of sex-linked biology and gender roles to disparities with trachoma. Emerg Infect Dis. 2004;10:2012-6.

30. Ferraz LC, Schellini AS, Padovani CR, Medina NH, Dalben I. Tracoma em crianças do ensino fundamental no município de Bauru - Estado de São Paulo, Brasil. Arq Bras Oftalmol. 2010;73:433-7. 